\title{
Collaborations
}

\author{
in \\ Fusion Research
}

January 1995

a white paper describing current experimental collaboration efforts and a view to the future needs and tools for experiments

This paper was written under the auspices of the DOE Fusion Computing Council (ECC)

by D. Barnes, S. Davis and P. Roney - Princeton Plasma Physics Laboratory

in collaboration with

P. Henline - General Atomics Corporation,

T. Casper - Lawrence Livermore Laboratory

M. Greenwald - Massachusetts Institute of Technology 


\section{Collaborations in Fusion Research}

\section{A View to the Future Needs and Tools for Experiments}

\section{Introduction}

This paper reviews current experimental collaborative efforts in the fusion community and extrapolates to operational scenarios for the Tokamak Physics Experiment (TPX) and the International Thermonuclear Experimental Reactor (ITER). Current requirements, available technologies and tools, and problems, issues and concerns are discussed. This paper specifically focuses on the issues that apply to experimental operational collaborations. Special requirements for other types of collaborations, such as theoretical or design and construction efforts, will not be addressed.

our current collaborative efforts have been highly successful, even though the tools in use will be viewed as primitive by tomorrow's standards. An overview of the tools and technologies in today's collaborations can be found in the first section of this paper.

The next generation of fusion devices will not be primarily institutionally based, but will be national (TPX) and international (ITER) in funding, management, operation and in ownership of scientific results. The TPX will present the initial challenge of real-time remotely distributed experimental data analysis for a steady state device. The ITER will present new challenges with the possibility of several remote control rooms all participating in the real-time operation of the experimental device. A view to the future of remote collaborations is provided in the second section of this paper.

\section{The Present State of Experimental Collaborations}

Considerable work has been done over the last few years to promote effective participation in fusion research experiments by collaborators at distant locations. Software tools have been developed and enhanced, and network capabilities have been extended in support of this activity. It is currently possible for researchers to control diagnostics, operate data 


\section{DISCLAIMER}

This report was prepared as an account of work sponsored by an agency of the United States Government. Neither the United States Government nor any agency thereof, nor any of their employees, make any warranty, express or implied, or assumes any legal liability or responsibility for the accuracy, completeness, or usefulness of any information, apparatus, product, or process disclosed, or represents that its use would not infringe privately owned rights. Reference herein to any specific commercial product, process, or service by trade name, trademark, manufacturer, or otherwise does not necessarily constitute or imply its endorsement, recommendation, or favoring by the United States Government or any agency thereof. The views and opinions of authors expressed herein do not necessarily state or reflect those of the United States Government or any agency thereof. 


\section{DISCLAIMER}

Portions of this document may be illegible in electronic image products. Images are produced from the best available original document. 
acquisition systems, integrate high-capacity computing and storage facilities at the remote site, view and provide results, and generally have access to all the computer-based information about the progress of the experiment. In these areas, we can largely declare that the needs of remote collaborators have been understood and can be met.

Addressing the goal of enhancing communication in general, efforts to provide audio and video connections with the control room have begun, and more extensive use of video-conferencing for meetings among various groups is planned.

\section{Three Examples of Remote Collaborations Currently in Operation in Fusion Research}

\section{C-MOD at The Massachusetts Institute of Technology}

The C-MOD data system at Massachusetts Institute of Technology (MIT) is designed around a cluster of networked workstations. Remote collaborators can access the standard data acquisition and control interfaces over the Internet (subject to locally imposed access restrictions). These include a shot cycle monitor, an interface to the plasma control system used for setting discharge parameters, interfaces to configure and modify data acquisition and analysis subsystems, monitor the data acquisition and analysis process, display raw or processed data, enter or retrieve data from an electronic logbook or other relational database tables. Data is also made directly available to remote users via an IP based remote data

server. In short - remote collaborators can access the same computer environment as local users. However, no special audio or video links have been implemented so far - a serious shortcoming that needs to be addressed.

\section{DIII-D at General Atomics Corporation}

Collaboration has been a large part of the magnetic fusion program at General Atomics (GA) since its inception. Both the DIII and DIII-D tokamaks have utilized the expertise of national and international collaborators. These include personnel from many of the U.S. national laboratories [Lawerence Livermore National Laboratory (LLNL), Argonne National Laboratory (ANL), Sandia National Laboratory (SNL), Oak Ridge National Laboratory (ORNL), Princeton Plasma Physics Laboratory (PPPL)], universities [including university of California Los Angelos (UCLA), University of California San Diego (UCSD), University of Southern California (USC), Johns Hopkins University, etc.] and foreign 
countries [Russia, Japan, Erance, England, Brazil, and more]. The collaboration with LINL has been especially strong. Several diagnostics are being operated remotely from LLNL, and experimental data is being analyzed between shots on IINL computers so that adjustments may be made before the next tokamak pulse. Computer systems at LINL are automatically notified of events in the shot sequence and these systems then can automatically respond to the events at $G A$. Computer functionality, such as Hewlett-Packard's Shared $X$ have been used to simultaneously present screens of output data at both GA and LINL. These areas of computer functionality are being enhanced to include more software, remote screens, shared software, and desktop shared video.

\section{TFTR at Princeton Plasma Physics Laboratory}

Remote collaborators on the Tokamak Fusion Test Reactor (TFTR) can now view any of the computerized (VAX-based) information about the experiment. Updates of the graphs or tabular database views occur as soon as new data becomes available. It is currently possible to specify an arbitrary selection of the available data waveforms for automatic plotting after every shot. In addition, any subset of the more than thirty plots calculated between shots by the TFTR higher level data analysis program can be automatically directed to any remote screen. Diagnostic-specific codes can be run automatically as data becomes available, or, for interactive codes, notification that the data are available can be requested. Information originally noted in the Physics Operator's log books or displayed on overhead transparencies (progress of the current experimental proposal) has been organized into computerized databases, and entering this data as a part of all routine operation has become the norm. For those diagnostics which must make control changes depending on changing experimental conditions, for instance to change sight-lines or move probes, fairly accurate knowledge of the current shot-clock time can be critical. The TFTR shot clock emulator was developed to satisfy this need. This program was the first to add the use of sound: programmable beeps accompanied major clock-cycle timing events. These were very helpful, since they made it less necessary to monitor that particular screen closely.

\section{Data Acquisition can be Centralized or Distributed}

Experience has been gained in doing data acquisition in both a centralized manner and using a distributed model. When the data acquisition system resides entirely at the central site, as for TFTR, it is important to 
give the remote user access to all. status, warning, and informational messages from the data acquisition and diagnostic control system, in addition to control of data acquisition and diagnostic parameters. When the data acquisition system has major components at the remote site, as in the collaboration by LLNL on the DIII-D tokamak at GA, both network bandwidth issues and the careful coordination of processing between the two sites become important.

Sometimes the remote site has computational and storage capabilities that could provide important services for the entire experiment, in addition to serving the users at that site. This has also been the case in the GA/LLNL collaboration, where a sophisticated interprocess communication system has made it possible to take advantage of a network of computers at LLNL, doing fully distributed processing, in conjunction with synchronizing signals originating at $G A$, and returning analyzed results for archival with shot data processed locally.

\section{Enhanced Communication is being Pursued}

The desirability of video and audio connections between the control room and remote collaborators has been evident for quite some time. Implementation of such links was delayed by high costs and by hardware and telephone network incompatibilities. This situation has changed dramatically with the availability of public domain desktop software for both audio and lowresolution video, using low-cost cameras and video capture boards. The software currently in use on TFTR is CU-SeeMe, from Cornell University, and MAVEN, from the University of Illinois; both are used on Macintosh platforms.

The desktop video links now in use involve cameras at the University of Wisconsin and Los Alamos National Laboratory (LANL), and at several locations in the TETR control room. Collaborators at any site can receive these transmissions on Macintoshes without any other special hardware except ordinary network connections. A microphone in the control room captures the public address system announcements, including the shot-clock countdown, and provides such a rich source of general information that TFTR staffers have begun to connect to it on their office computers.

Additional camera views are currently being planned, including one of the control room annex, where the daily $8: 30$ a.m. meetings occur. Initially, remote collaborators will only be able to see and hear these 
meetings; hopefully, active participation will eventually also become possible.

\section{A View to the Future}

\section{Exciting But Uncertain}

This is both an exciting and difficult time to be predicting technological developments and trends. With technology rapidly changing in response to tremendous economic opportunities, the present state of technology is sometimes even difficult to track. Social response is another factor what makes technology predictions difficult. Some apparently useful products will fail while other products that are less obviously useful on the surface may overtake our community by storm. The following discussions need to be viewed in light of these uncertainties.

\section{QPPORTUNITIES:}

\section{Networking}

An excellent net:work infrastructure is the most basic technical requirement for enabling effective collaborations. Nearly every remote function we perform demands fast reliable connectivity.

The current Energy Sciences Network (ESNET) on which the fusion community relies currently runs primarily at 1.5 Megabits per second. This speed will shortly increase to 45 Megabit per second and within several years will pass the Gigabit per second realm.

International networking speeds are problematic today. Current attempts at overseas collaborations are seriously hampered by the lack of adequate network bandwidth. Eventually overseas network speeds will increase, but these network links are expected to continue to lag ESNET capability.

The technology to support local area networking improvements is clearly becoming widely available both at the backbone level and at the machine interface level. Over the next several years, laboratories and 
institutions which intend to collaborate will need to continually invest in improving their infrastructure.

Historically, with every increase in networking speeds, a corresponding increase in usage has occurred. our community has an insatiable demand for network throughput. Collaborators will need predictable connectivity in order to operate successfully. To support deterministic responses for both controlling and observing equipment operation, as well as for accessing required data, emerging technologies such as dedicated virtual circuits must be implemented.

Networking technology is however, being developed with a timeliness that will provide the required support for future collaborations.

\section{The Projection of a Presence}

To remain an active and contributing member of a research team, a collaborating engineer or physicist needs to maintain a "presence" at the experiment. This "presence" is not only in the control room, but also in other person to person contact situations such as scheduling meetings, research meetings, and shift turnover meetings. In the normal on-site research effort, hallway and lunch time conversation are also important. Many valuable communications involve chance meetings by colleagues.

The next several paragraphs address how evolving technologies might be used to enhance a collaborator's "presence".

\section{Video Conferencing}

One technology for projecting a collaborator's "presence" is the use of Video Conferencing, both at the conference room level and the desktop level.

High end video conferencing (VC) systems are proliferating rapidly. These VC systems provide excellent capabilities for holding point to point or multipoint conferences. The systems feature good quality video transmissions and excellent full duplex audio.1 High end VC systems also transmit overhead projections and allow for the integration of FAX transmissions and personal computer communications. For regularly scheduled meetings, these systems can work extremely well. Minimal systems today cost $\$ 25,000$ to $\$ 50,000$, however their cost is expected to drop rapidly.

1 Full duplex audio allows both parties to talk at the same time. 
Within the fusion community, these systems will initially rely on connectivity through commercial ISDN carriers and will not affect our network loads. When TPX and ITER begin operation, these systems should be well integrated with desktop systems.

Desktop conferencing systems are much less expensive and are just now beginning to proliferate. Any hesitation in implementation is due to the lack of bandwidth on the wide area and local networks.

The capabilities of desktop systems are rapidly expanding. The integration of voice as well as video will revolutionize the way we do business. In a simple desktop call, a colleague can open a window to their location and enable full point to point or multipoint working conversazions. Collaborators will have the ability to view and interact with a colleague's screen and have the tools needed to discuss working documents and/or pertinent reference information.

\section{Future Video}

In the video arena, the major developments will be converting all video systems to digital. Reasonably priced digitally based video servers will be available in the near future. These systems will rely on highly efficient compression algorithms and should be available with large storage systems. For fusion researchers this will allow the recording of many video signals which today are only available in real time. These views will likely include plasma $T V$ and other diagnostic video signals, surveillance cameras, and important meetings. The ability to recall audio and video from an archive of predetermined recordings will enable both local and remote collaborators to keep better informed on the present experimental direction, plans, and issues.

\section{Flat Screens/White Boards}

Flat screen technology advances are likely to enhance our ability to communicate both locally and remotely. The US government has recognized the importance of flat displays and alsc that foreign industries have large development efforts in this area. As a result, the US has begun a number of initiatives to encourage US industry to compete in this area. The current cost of large flat screens is currently quite high due primarily to the infancy of manufacturing technologies. Through improvements in production techniques and foreign competition, flat screen technology should rapidly fall in price, making it widely available for a number of innovative uses. 
Large touch sensitive flat screens with high definition television type resolution could become very popular replacements for current office blackboards. Such screens coupled with powerful processors could provide a number of new or enhanced functions. A system could be used to provide a blackboard surface which could be erased, saved, or retrieved from a previous discussion. The surface could be used locally or viewed by a remote collaborator who is made visible in a corner of the screen through video conferencing software. Incoming (video) phone calls might also be directed toward the screen. Flat screen technology might also be used in conference rooms to enable presentations and discussions.

\section{Location Independence}

Personal communication systems are systems that provide communications to an individual regardless of location. Such systems are currently being developed and tested in a variety of forms.

One concept is the personal phone number. An individual carries a "phone" at all times. A global communications system tracks the location of the individual and directs incoming calls to them, whether in the office, at home, in a hallway or on a plane.

Another similar concept provides all employees with an electronic ID badge. The badge enables a local communications system to know where the employee is at all times while on site. Incoming calls are directed to the telephone nearest the individual. The smart badge also contains a switch to allow am "I'm busy" response which would switch the caller to a voice mail system. This system also allows an individual to sit down at any computer terminal and have immediate access to their own desktop and file system. The smart badge concept could be easily expanded to couple a number of sites together so that collaborators at any site would appear to be integrated into a single system.

\section{ISSUES:}

\section{Personnel and Equipment Protection}

One of the biggest concerns encountered when discussing remote, collaborative operation of experimental devices is the issue of authorized or unauthorized users intentionally or unintentionally operating devices which could harm people or equipment. 
It is necessary to recognize this concern and to define remote operation as a requirement of the experimental device early on ir the design phase of that device. This will then insure that appropriate safety features are fully designed and integrated into the device and systems controlling the device.

\section{security}

Our remote collaborations rely heavily on access to current networks which are, in most cases "wide open" in terms of security. Generally, the extent of security employed today is the requirement for identification to a system via a password. These passwords are transmitted over the Internet and could be easily intercepted by moderately educated hackers. Better security protocols are now growing in use and could be required for future collaborations. The most popular current system, Kerberos, relies on a public and private key system for encoding and decoding all messages including the transmission of the passwords themselves.

\section{Data Dependencies}

Another concern is for the integrity of the data at all stages, from raw data points to fully analyzed data sets. For example, a calculation of results from an experiment might rely on input data from several diagnostics. Physicists could conceivably be operating their diagnostics from different remote sites. potentially, at a later time, a calibration could change such that the input from one diagnostic should be recalculated by all who have used that data in subsequent calculations. The management and coordination of data from an experiment as complicated as a Tokamak could fast become a nightmare. This is, however, not a technical problem, but rather a management and administrative problem that if recognized early in the design phase of the data acquisition and archival system can be addressed by management and administrative solutions. It should be noted that this issue is not unique to distributed and/or remotely located systems, but is one that we grapple with today in our purely local systems.

\section{Common User Interfaces}

A concern that nany physicists express today is that much time and many dollars have been invested in existing software. Rewriting major codes to accept alien data formats seems to be a insurmountable effort. 
Additionally, individual experimenters at different sites have become accustomed to familiar user interfaces or to particular operating systems. There seems to be an inertia to change. We predict, however, that over the next several years this inertia will molt into action. Along with the development of Graphical User Interfaces (GUI) and 5th generation languages the tools to convert existing coded to machine interoperable codes will be developed and readily commercially available. The motivation for conversion may initially be for machine cycles and will happen well before the need for conversion for TPX or ITER data analysis.

\section{Sociological Considerations}

Sociological issues are a final great concern. Some people are resistant to change, and increased collaboration brings with it many changes. These changes involve both technical and interpersonnel aspects of dealing with people. New skills will be needed to deal with remote video, white boards, teleconferencing, virtual reality, and the other mechanical parts that are used to increase remote collaboration. A more difficult arena is to develop relationships with other people, when the amount of actual face-to-face contact is minimum. Ways must be developed to keep the same llook and feel' of interpersonal relationships, so that trust and good working relationships can be built.

\section{Conclusions}

\section{Remote Participation and Operation will be Ordinary}

With the advancement of telecommunications and computing power over the next decade, the scientific community will have the opportunity to dramatically revise the definition of what constitutes direct participation in experiments. We anticipate that all the collaborative "parties" will be able to participate directly and meaningfully in, as well as monitor, the operations of the TPX, and eventually the ITER, using remote sites located at each participating institution.

\section{From Single Point to Large Scale Collaborations}

The concept of extensive remote participation in major experiments is not new, it is a current reality but on a modest scale. Existing communication technology has allowed scientists to remotely access experiments and other collaborations world-wide, to employ remote, real 
time data access, and in some cases to monitor and control specific diagnostic capabilities from home sites.

Many steps have been made in mechanical means to enhance collaboration. These include software and hardware to facilitate remote communication. The tools available now have been tried only in limited instances, and have dealt only with a few people. For TPX and ITER, much larger groups of people and more collaborators will be simultaneously involved. Additionally the scope will be expanded to include remote comprehensive tokamak control.

\section{A Vision for ITER}

By the year 2000, we predict that technology advancements will allow for full remote operation of the ITER from several control rooms sited at distant locations around the world. We also predict that the utilization of these technologies, in particular the communication technologies such as video and white boards will have become so ordinary, that the sociological concerns of today will be memories of a past generation. Management issues identified above are clearly resolvable, especially in the time scale involved. We are, however, only in the position of identifying and defining these areas to management; not in a position to suggest the administrative solutions. Eigure 1. depicts our vision for ITER operations. 
Figure 1.
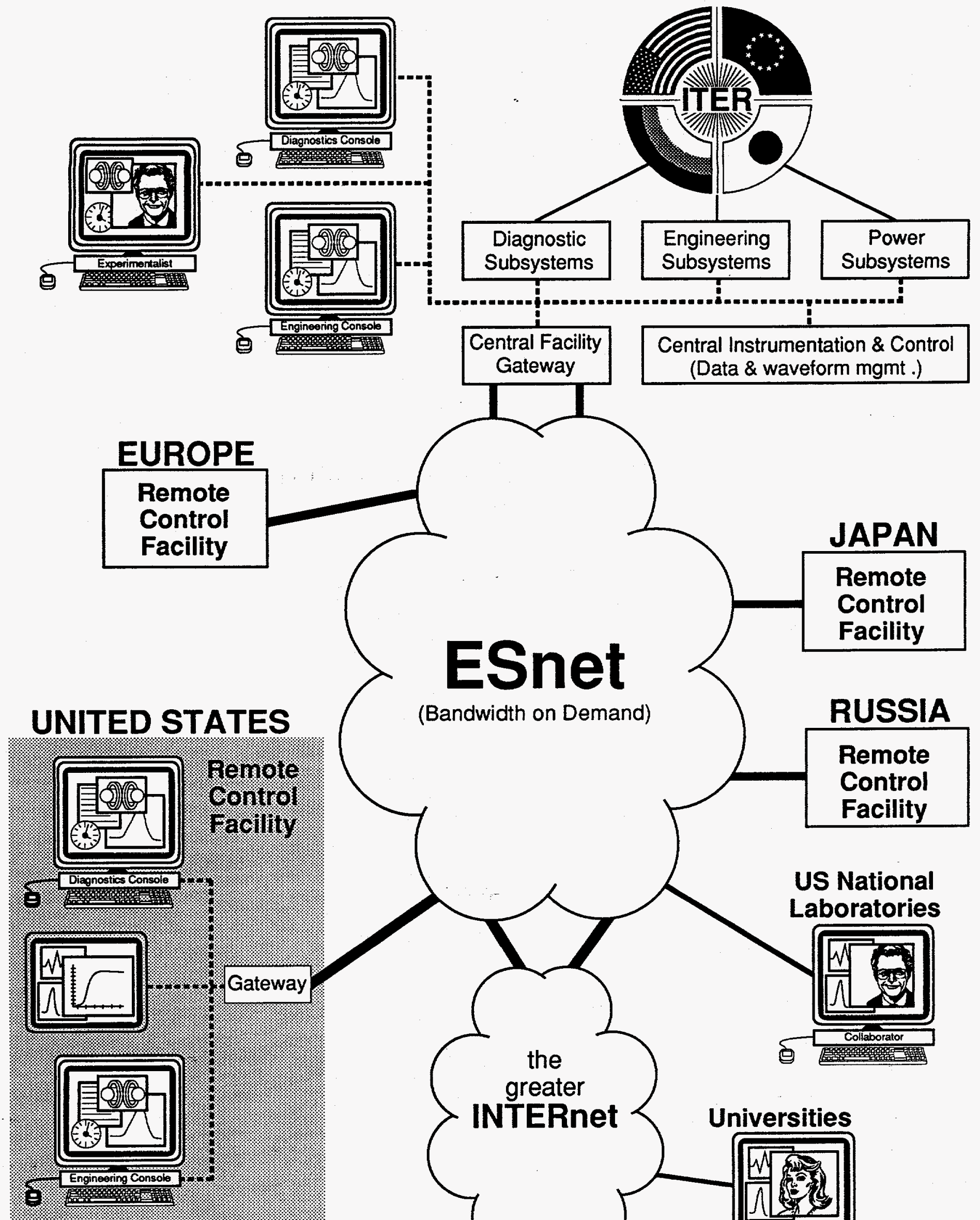

(Bandwidth on Demand)

RUSSIA

Remote Control Facility

JAPAN

Remote Control Facility

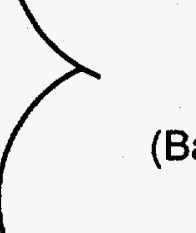


Dr. F. Paoloni, Univ. of Wollongong, AUSTRALIA

Prof. R.C. Cross, Univ. of Sydney, AUSTRALIA

Plasma Research Lab., Australian Nat. Univ., AUSTRALIA

Prof. I.R. Jones, Flinders Univ, AUSTRALIA

Prof. F. Cap, Inst. for Theoretical Physics, AUSTRIA

Prof. M. Heindler, Institut für Theoretische Physik, AUSTRIA

Prof. M. Goossens, Astronomisch Instituut, BELGIUM

Ecole Royale Militaire, Lab. de Phy. Plasmas, BELGIUM

Commission-European, DG. XII-Fusion Prog., BELGIUM

Prof. R. Bouciqué, Rijksuniversiteit Gent, BELGIUM

Dr. P.H. Sakanaka, Instituto Fisica, BRAZIL

Prof. Dr. I.C. Nascimento, Instituto Fisica, Sao Paulo, BRAZIL Instituto Nacional De Pesquisas Espaciais-INPE, BRAZIL

Documents Office, Atomic Energy of Canada Ltd., CANADA

Ms. M. Morin, CCFM/Tokamak de Varennes, CANADA

Dr. M.P. Bachynski, MPB Technologies, Inc., CANADA

Dr. H.M. Skarsgard, Univ. of Saskatchewan, CANADA

Prof. J. Teichmann, Univ. of Montreal, CANADA

Prof. S.R. Sreenivasan, Univ. of Calgary, CANADA

Prof. T.W. Johnston, INRS-Energie, CANADA

Dr. R. Bolton, Centre canadien de fusion magnétique, CANADA

Dr. C.R. James, Univ. of Alberta, CANADA

Dr. P. Lukác, Komenského Universzita, CZECHO-SLOVAKIA

The Librarian, Culham Laboratory, ENGLAND

Library, R61, Rutherford Appleton Laboratory, ENGLAND

Mrs. S.A. Hutchinson, JET Library, ENGLAND

Dr. S.C. Sharma, Univ. of South Pacific, FIJI ISLANDS

P. Mähönen, Univ. of Helsinki, FINLAND

Prof. M.N. Bussac, Ecole Polytechnique, FRANCE

C. Mouttet, Lab. de Physique des Milieux lonisés, FRANCE

J. Radet, CEN/CADARACHE - Bat 506, FRANCE

Prof. E. Economou, Univ. of Crete, GREECE

Ms. C. Rinni, Univ. of loannina, GREECE

Preprint Library, Hungarian Academy of Sci., HUNGARY

Dr. B. DasGupta, Saha Inst. of Nuclear Physics, INDIA

Dr. P. Kaw, Inst. for Plasma Research, INDIA

Dr. P. Rosenau, Israel Inst. of Technology, ISRAEL

Librarian, Intemational Center for Theo Physics, ITALY

Miss C. De Palo, Associazione EURATOM-ENEA , ITALY

Dr. G. Grosso, Istituto di Fisica del Plasma, ITALY

Prof. G. Rostangni, Istituto Gas Ionizzati Del Cnr, ITALY
Dr. H. Yamato, Toshiba Res \& Devel Center, JAPAN

Prof. I. Kawakami, Hiroshima Univ., JAPAN

Prof. K. Nishikawa, Hiroshima Univ., JAPAN

Librarian, Naka Fusion Research Establishment, JAERI, JAPAN

Director, Japan Atomic Energy Research Inst., JAPAN

Prof. S. Itoh, Kyushu Univ., JAPAN

Research info. Ctr., National instit. for Fusion Science, JAPAN

Prof. S. Tanaka, Kyoto Univ., JAPAN

Library, Kyoto Univ., JAPAN

Prof. N. Inove, Univ. of Tokyo, JAPAN

Secretary, Plasma Section, Electrotechnical Lab.; JAPAN

Dr. O. Mitarai, Kumamoto Inst. of Technology, JAPAN

Dr. G.S. Lee, Korea Basic Sci. Crr., KOREA

J. Hyeon-Sook, Korea Atomic Energy Research Inst., KOREA

D.I. Choi, The Korea Adv. Inst. of Sci. \& Tech., KOREA

Prof. B.S. Liley, Univ. of Waikato, NEW ZEALAND

Inst of Physics, Chinese Acad Sci PEOPLE'S REP. OF CHINA

Library, Inst. of Plasma Physics, PEOPLE'S REP. OF CHINA

Tsinghua Univ. Library, PEOPLE'S REPUBLIC OF CHINA

Z. Li, S.W. Inst Physics, PEOPLE'S REPUBLIC OF CHINA

Prof. J.A.C. Cabral, Instituto Superior Tecnico, PORTUGAL

Prof. M.A. Hellberg, Univ. of Natal, S. AFRICA

Prof. D.E. Kim, Pohang Inst. of Sci. \& Tech., SO. KOREA

Prof. C.I.E.M.A.T, Fusion Division Library, SPAIN

Dr. L. Stenflo, Univ. of UMEA, SWEDEN

Library, Royal Inst. of Technology, SWEDEN

Prof. H. Wilhelmson, Chalmers Univ. of Tech., SWEDEN

Centre Phys. Des Plasmas, Ecole Polytech, SWITZERLAND

Bibliotheek, Inst. Voor Plasma-Fysica, THE NETHERLANDS

Asst. Prot. Dr. S. Cakir, Middle East Tech. Univ., TURKEY

Dr. V.A. Glukhikh,Sci. Res. Inst. Electrophys.I Apparatus, USSR

Dr. D.D. Ryutov, Siberian Branch of Academy of Sci., USSR

Dr. G.A. Eliseev, I.V. Kurchatov Inst., USSR

Librarian, The Ukr.SSR Academy of Sciences, USSR

Dr. L.M. Kovrizhnykh, Inst. of General Physics, USSR

Kernforschungsanlage GmbH, Zentralbibliothek, W. GERMANY

Bibliothek, Inst. Für Plasmaforschung, W. GERMANY

Prof. K. Schindler, Ruhr-Universitát Bochum, W. GERMANY

Dr. F. Wagner, (ASDEX), Max-Planck-Institut, W. GERMANY

Librarian, Max-Planck-Institut, W. GERMANY 